\title{
Targeting TRP Ion Channels for Itch Relief
}

\author{
Xuming Zhang
}

Rowett Institute of Nutrition and Health \& Institute of Medical Sciences, University of Aberdeen, Foresterhill, Aberdeen AB25 2ZD, United Kingdom

Keywords: TRP ion channels / itch/ Pain/ somatosensory transduction

Corresponding author: Dr. Xuming Zhang, Rowett Institute of Nutrition and Health \& Institute of Medical Sciences, University of Aberdeen, Foresterhill, Aberdeen AB25 2ZD, United Kingdom

Tel: +44 1224 437366; E-mail: x.zhang@abdn.ac.uk 


\begin{abstract}
:
Acute itch (pruritus) is unpleasant and acts as an alerting mechanism for removing irritants. However, severe chronic itch is debilitating and impairs the quality of life. Rapid progress has been made in recent years in our understanding of the fundamental neurobiology of itch. Notably, several temperature-sensitive Transient Receptor Potential (thermo-TRP) ion channels have emerged as critical players in many types of itch, in addition to pain. They serve as markers that define the itch neural pathway. Thermo-TRP ion channels are thus becoming attractive targets for developing effective anti-pruritic therapies.
\end{abstract}

\title{
1. Introduction
}

Itch is classically defined as an unpleasant cutaneous sensation which triggers the desire to scratch. It is often caused in the local affected skin by itch-producing agents (pruritogens) including amines, proteases, neuropeptides, cytokines, inflammatory metabolites and some drugs (Akiyama and Carstens, 2013;Ross et al., 2010), and can also be a widespread symptom associated with systemic diseases, such as autoimmune diseases, liver diseases, metabolic diseases and malignant cancers. Itch can be acute and transient (e.g., by biting insects). Acute itch is considered to be a defence mechanism that alerts the body to remove irritants; however, in some cases acute itch can progress to become persistent and chronic. Chronic itch is pathological and debilitating to the well-being of humans. Itch was classified into four main categories: pruritoceptive (caused by pruritogenic agents), neurogenic, neuropathic (e.g. lesions in the nervous sytem) and psychogenic, according to the pathophysiology of itch (Yosipovitch et al., 2003;Greaves, 2007).

Itch is historically linked to pain because of their close relationship and the fact that pain inhibits itch. However, compared to extensive research on pain, itch has received less attention and is still an unmet clinical need. The lack of effective itch therapies requires a deeper insight into the molecular underpinnings of itch. A growing body of recent evidence reveals TRP ion channels as key players of both acute and chronic itch elicited by a diversity of pruritogens. TRP ion channels are thus becoming alternative targets for itch treatment.

TRP ion channels are a large family of nonselective cation ion channels comprising seven subfamilies: TRPC (canonical), TRPV (vanilloid), TRPM (melastatin), TRPA (ankyrin) and TRPN (NOMPC-like), TRPP (polycystin) and TRPML (mucolipin) (Venkatachalam and Montell, 2007;Nilius and Owsianik, 2011). They are widely expressed in the skin, sensory neurons and a number of other tissues, and implicated in widespread functions ranging from sensory physiology (e.g., phototransduction, chemo-, thermo-, and mechano-sensation) to disorders in many systems such as the cardiovascular and respiratory systems (Nilius et al., 2007). Of note, several temperature-sensitive ion channels (known as thermo-TRP ion channels), such as TRPV1, TRPA1, TRPM8 and TRPV3, have been demonstrated to be essential for the transduction of pain (Julius, 2013;Brederson et al., 2013;Huang et al., 2006). Interestingly, these same TRP ion channels also participate in the sensation of itch. The role of thermo-TRP ion channels in itch sensation is the focus of the review. The concomitant 
involvement of Thermo-TRP ion channels in transducing both pain and itch may underlie the intimate and promiscuous relationship between pain and itch.

\section{Neural mechanisms of itch}

Itch has long been considered as a submodality of pain, with low intensity of stimuli eliciting itch and high intensity of stimuli causing pain (McMahon and Koltzenburg, 1992). Indeed both itch and pain are mainly transduced by the $\mathrm{A} \delta$ and $\mathrm{C}$ polymodal nociceptive fibers innervated in peripheral tissues such as skin (Ringkamp et al., 2011). However, recent research lends support to the population coding based selectivity model. According to this model, pain and itch are transduced separately by two subpopulations of sensory neurons: pain-selective (nociceptive) and itch-selective (pruriceptive), though pruriceptive neurons are polymodal and can also be activated by nociceptive stimuli (algogens) (Lamotte et al., 2014;Patel and Dong, 2010). Therefore, a selective activation of pruriceptive neurons causes itch, regardless of the nature of stimuli, nociceptive or pruriceptive; in contrast, a broad activation of both nociceptive and pruriceptive neurons by nociceptive stimuli causes pain, instead of itch, because the dominant activation of nociceptive neurons inhibits and overrides the activity of the pruriceptive pathway(Roberson et al., 2013;Han et al., 2013;Lagerstrom et al., 2010;Liu et al., 2010b), an event which maybe mediated by the release of dynorphin, a kappa opioid, from the central inhibitory Bhlhb5 ${ }^{+}$interneurons (Ross et al., 2010; Kardon et al., 2014). In support of this model, selective ablation of a subpopulation of the itch-specific Dorsal Root Ganglion (DRG) neurons from mice significantly reduced itch-associated behaviours elicited by various pruritogens in mice, but spared pain behaviours (Han et al., 2013). On the other hand, pain behaviours were markedly impaired, but itching responses were even enhanced in mice in which the nociceptive neuron transmission has been selectively silenced (Liu et al., 2010b;Lagerstrom et al., 2010), suggesting that the nociceptive pathway constitutively inhibits the itch transducing pathway.

\section{The involvement of Thermo-TRP ion channels in itch}

There are two types of itch according to the category of pruritogens: histamine-dependent (histaminergic) and histamine-independent (non-histaminergic) (Table 1). The histaminergic itch is caused by histamine, and thus can be effectively treated by anti-histamines. However, the majority of itch are non-histaminergic, and cannot be effectively treated by the antihistamines. For example, chloroquine, a drug used to treat malaria, can cause intolerable itch resistant to the anti-histamine therapy.

\subsection{Histaminergic itch and TRPV1}

It has long been recognized that histamine provokes itching by acting on the histamine receptor H1R on sensory nerve endings (Greaves and Davies, 1982). But it was not known how activation of H1R causes the excitation of pruriceptive sensory neurons until 2007, when Shim et al discovered that activation of H1R opens TRPV1, a heat gated ion channel that also responds to capsaicin and acid, leading to the excitation of a subpopulation of sensory neurons (Shim et al., 2007). TRPV1 was then implicated in transducing histaminergic itch. Consistent with this idea, the majority of histamine-responding DRG neurons co-expressed TRPV1 (TRPV1 ${ }^{+}$) (Figure 1), and histaminergic itch was significantly reduced by deleting 
the TRPV1 gene (Shim et al., 2007). Furthermore, histamine-induced itching response (scratching) was eliminated after prior silencing the TRPV1 ${ }^{+}$pruriceptive neurons through prior co-injection of histamine with the membrane impermeable lidocaine derivative QX-314, a sodium channel blocker which acts by inactivating sodium currents after entering neurons through the large pore of opened TRPV1 (Roberson et al., 2013). The same manipulation, however, did not affect capsaicin-evoked pain behaviour (wiping)(Roberson et al., 2013). These findings suggest that there is a subpopulation of TRPV $1^{+}$neurons that specifically mediates itch, but is dispensable for pain, and that TRPV1 is a main downstream coupling ion channel of H1R, mediating histaminergic itch.

It should be noted that histamine-induced scratching was only partially reduced by deleting the TRPV1 gene (Shim et al., 2007). Strikingly, the histaminergic itch was completely abolished by deleting the TRPV1 ${ }^{+}$neurons (Imamachi et al., 2009), implying that other transducers, in addition to TRPV1, contained within the TRPV $1^{+}$neurons are also involved. Consistent with this suggestion, histamine still induced intracellular calcium $\left(\left[\mathrm{Ca}^{2+}\right]_{\mathrm{i}}\right)$ increases in the DRG neurons lacking TRPV1(Shim et al., 2007), and a proportion of histamine-excited neurons (11.4\%) did not respond to capsaicin and thus did not co-express TRPV1(Figure 1). One possibility for mediating TRPV1-independent responses is the histamine receptor H4R, because it has been shown that selective activation of H4R is sufficient to trigger $\left[\mathrm{Ca}^{2+}\right]_{\mathrm{i}}$ increases in the DRG neurons and itching responses in animals (Bell et al., 2004;Rossbach et al., 2011). However, downstream coupling ion channels and signalling mechanisms activated by H4R remain to be established.

\subsection{Non-histaminergic itch and TRPA1}

The mechanisms of the histaminergic itch had been sought for centuries. By contrast, the non-histaminergic itch has received attention just in recent years. It is caused by a diversity of pruritogens (Table 1), such as chloroquine (CQ), serotonin, endothelin-1 (ET-1) and cowhage etc., of which CQ has been exploited as a primary chemical tool towards our understanding of the non-histaminergic itch.

In contrast to TRPV1-mediated histaminergic itch, CQ induces itching by exciting the TRPA1 ion channel after binding to the CQ receptor MrgprA3, a Mas related G protein coupled receptor (Wilson et al., 2011;Han et al., 2013;Liu et al., 2009). In support of this concept, a strong itching deficit caused by CQ was observed either by deleting the TRPA1 gene from mice or by electrically silencing the TRPA $1^{+}$neurons or by ablating the MrgprA3 ${ }^{+}$ neurons (Wilson et al., 2011;Han et al., 2013;Roberson et al., 2013). Although TRPA1 was initially identified as a transducer for pain (Julius, 2013), a specific subpopulation of TRPA $1^{+}$ neurons is indispensable for mediating itch, not for pain. This conclusion is based on the fact that TRPA1-mediated pain behaviour induced by injection of AITC, an agonist to TRPA1, is not altered after selective silencing the TRPA $1^{+}$pruriceptive neurons by prior co-injection of CQ and QX-314, a process, however, does abolish CQ-elicited itching (Roberson et al., 2013). This subpopulation of the itch-specific TRPA $1^{+}$neurons seems to also underlie the actions of many other non-histaminergic pruritogens, such as BAM8-22(Wilson et al., 2011), SLIGRL (Roberson et al., 2013;Liu et al., 2011), IL-31(Cevikbas et al., 2014) and oxidative 
stress (Liu and Ji, 2012). As with CQ, these non-histaminergic pruritogens co-excited $\mathrm{TRPA}^{+}$neurons, and their elicited itching behaviours were also correspondingly reduced in mice lacking TRPA1. However, we have recently found that TRPA1 mediates responses from only a subpopulation of CQ-sensitive neurons (Than et al., 2013). More than half of CQ-sensitive neurons did not co-express TRPA1, and their responses were not prevented by blocking TRPA1, instead were blocked by an antagonist to the TRPC3 ion channel, suggesting that TRPC3 mediates the actions of CQ in this subpopulation of CQ-sensitive neurons (Than et al., 2013). It remains to be determined whether this population of TRPC3 ${ }^{+}$ neurons contributes to itch.

In addition to acute itch, TRPA1 is involved in chronic itch such as atopic dermatitis and other inflammation associated dermatitis. The expression of TRPA1 was increased in skin lesions from patients with chronic itch (Oh et al., 2013;Yang et al., 2014). Behaviourally the itching response was significantly diminished in mice with chronic itch either by blocking TRPA1 pharmacologically or by deleting TRPA1 genetically (Wilson et al., 2013a;Liu et al., 2013;Wilson et al., 2013b;Oh et al., 2013). Furthermore, TRPA1 deficient mice exhibited less pathological changes in the affected skin in a mice dry-skin model (Wilson et al., 2013a;Liu et al., 2013), presumably caused by reduced neurogenic inflammation provoked by the activity of TRPA1(Bautista et al., 2013). Interestingly, thymic stromal lymphopoietin (TSLP) was demonstrated as an important cytokine that directly excites TRPA1, resulting in enhanced scratching behaviours associated with atopic dermatitis in animals (Wilson et al., 2013b;Jariwala et al., 2011). Given the prominent role of TRPA1 in itch, it is promising to combat acute and chronic itch by targeting the TRPA1 ion channel.

\subsection{Relationship between TRPV1- and TRPA1-mediated itch}

It has been reported that TRPA1 is largely contained within a subpopulation of TRPV1expressing neurons (Story et al., 2003). However, it was not known whether the TRPV1 ${ }^{+}$ pruriceptive neurons that mediate histaminergic itch, overlap with the TRPA $1^{+}$pruriceptive neurons that mediate non-histaminergic itch. Answer to this question has been suggested by the following behavioural and cellular evidence. First, non-histaminergic itching induced by CQ was not affected by either deleting the TRPV1 gene or by specifically silencing histamine activated TRPV1 ${ }^{+}$pruriceptive neurons, but substantially reduced by either deleting the TRPA1 gene or by silencing TRPA $1^{+}$pruriceptive neurons (Wilson et al., 2011;Roberson et al., 2013); on the other hand, histamine-elicited itching was reduced by deleting or silencing TRPV $1^{+}$neurons, but not by silencing TRPA $1^{+}$pruriceptive neurons (Shim et al., 2007; Imamachi et al., 2009;Roberson et al., 2013). Therefore, the histaminergic itch and CQinduced itch are transduced by two largely separate and non-overlapping populations of $\mathrm{TRPV}^{+}{ }^{+}$and TRPA $1^{+}$pruriceptive neurons, respectively. It also suggests that histamine and CQ-activated pruriceptive pathways divide at the outset in the peripheral DRG neurons. Consistent with behavioural studies, histamine and CQ excited two largely separate populations of DRG neurons (Roberson et al., 2013). However, for some non-histaminergic pruritogens such as IL-31 and leukotriene B-4 (LTB-4), both TRPV1 and TRPA1 are required for mediating the excitation of sensory neurons and itching behaviour in mice (Cevikbas et al., 2014;Rabenhorst and Hartmann, 2014;Fernandes et al., 2013), presumably 
pruritic receptors for these cytokines are expressed in subsets of both TRPA $1^{+}$and TRPV $1^{+}$ pruriceptive neurons.

In summary, the TRPV $1^{+}$and TRPA $1^{+}$pruriceptive neurons represent two discrete subpopulations of itch-specific neurons, in which TRPV1 and TRPA1 are the main downstream coupling ion channels that mediate the excitation of pruriceptive neurons evoked, respectively, by histamine and non-histaminergic pruritogens including CQ, BAM8-22, SLIGRL and TSLP (Table 1).

\subsection{Possible role of other TRP ion channels in mediating non-histaminergic itch}

Histamine and CQ have served as powerful fishing tools in disclosing the two subpopulations of itch-specific TRPV1 ${ }^{+}$and TRPA $1^{+}$neurons in the itch neural pathway. Accumulating evidence also suggests that there exist other types of itch-transducing neurons independently of either TRPV1 or TRPA1 (see below). In these cases, other non-histaminergic pruritogens (Table 1) will provide further impetus in searching for molecules and ion channels that are responsible for other itch transducing mechanisms.

ET-1, serotonin and imiquimod: ET-1 induces both nociceptive and itching behaviour when injected intradermally. These effects are mediated by the ETAR receptor (Liang et al., 2010;Kido-Nakahara et al., 2014; Trentin et al., 2006;Gomes et al., 2012). TRPV1 ${ }^{+}$

pruriceptive neurons were found to be critical for mediating itching responses induced by ET1, because ET-1 elicited scratching was substantially reduced after selective killing the central terminals of TRPV1-expressing nociceptors through intrathecal injection of capsaicin (Imamachi et al., 2009). With the same approach, TRPV1 ${ }^{+}$neurons were also found to be essential for itching elicited by serotonin and imiquimod (Imamachi et al., 2009;Kim et al., 2011). However, itching behaviours induced by all these pruritogens were not significantly different between TRPV1 knockout mice and wild type littermates (Imamachi et al., 2009; Liu et al., 2010a;Kim et al., 2011), suggesting that the TRPV1 ion channel per se is not required for ET-1-, serotonin- and imiquimod-induced itching, and that other unknown ion channels expressed within the TRPV $1^{+}$neurons are involved. Consistent with the behavioural studies, the percentage of DRG neurons responding to ET-1 was not significantly reduced by either deleting TRPV1 or TRPA1(Kido-Nakahara et al., 2014). Taken together, TRPV1 ${ }^{+}$ pruriceptive neurons comprise functionally diversified subpopulations and contain, in addition to TRPV1, other unknown, potentially TRP ion channels that mediate scratching responses caused by ET-1, serotonin and imiquimod.

$\beta$-alanine: $\beta$-alanine is an $\beta$ amino acid. It causes an itching and tingling sensation after consumption. Interestingly, $\beta$-alanine induced itching by activating a subpopulation of neurons expressing Mrgprd, a G protein coupled receptor (Liu et al., 2012). Furthermore, $\beta$ alanine excited neurons did not respond to either histamine or CQ (Liu et al., 2012), suggesting that the Mrgprd $^{+}$neurons define a separate subpopulation of pruriceptive neurons, distinct from the TRPV $1^{+}$and TRPA $1^{+}$pruriceptive neurons. However, ion channels downstream of Mrgprd activation remain to be established. 
Cowhage: Cowhage spicules have long been recognized to be able to induce a strong itching sensation. The underlying mechanisms, however, remain obscure. It appears that cowhageinduced itch is not correlated with histamine-induced itch, because cowhage and histamine activate largely separate sets of peripheral afferent $\mathrm{C}$ fibres and also two largely independent populations of spinothalamic tract neurons (STT) neurons (Johanek et al., 2007;Davidson et al., 2007;Davidson et al., 2012;Papoiu et al., 2011;Johanek et al., 2008). The active component of cowhage has been identified as mucunain, a cysteine protease (SHELLEY and ARTHUR, 1955). It acts on protease-activated receptor (PAR) 2 and 4 on DRG neurons to trigger calcium influx(Reddy et al., 2008). However, downstream ion channels coupled to PAR2 and PAR4 remain undetermined. Several TRP ion channels have been suggested including TRPV1, TRPV4 and TRPA1(Nakagawa and Hiura, 2013), because the PAR receptors were co-expressed with these TRP ion channels in DRG neurons(Amadesi et al., 2004;Dai et al., 2007;Grant et al., 2007;Dai et al., 2004).

Cholestatic pruritus: Cholestatic liver diseases are often accompanied with a severe and intractable itching sensation. It has recently been demonstrated that increased bile acids (BAs) in the circulation, at least in part, are responsible for cholestatic pruritus (Alemi et al., 2013). BAs increased the excitability of a subset of DRG neurons by acting on the G protein coupled receptor TGR5, leading to the release of pruritogenic gastrin-releasing peptide (GRP) (Alemi et al., 2013). This process was recently demonstrated to be mediated by activating and sensitizing TRPA1 following TGR5 activation (Lieu et al., 2014). Apart from BAs, lysophosphatidic acid (LPA) was also identified as pruritogenic agents from cholestatic patients (Kremer et al., 2010). It will be interesting to determine on which subpopulations of pruriceptive neurons (TRPV1 ${ }^{+}$or TRPA $1^{+}$or others) LPA act in the future.

\section{Itch signalling mechanisms}

Most painful stimuli (algogens) excite nociceptive neurons often by directly targeting ion channels on sensory neurons. For example, capsaicin and mustard oil act on TRPV1 and TRPA1, respectively to produce nociception (Julius, 2013). By contrast, nearly all pruritogens elicit itch by acting on pruritic receptors on sensory neurons, most of which are GPCRs. Activated pruritic receptors then trigger the activation of a downstream ion channel, often a TRP ion channel, through an intracellular signalling coupling mechanism, leading to consequent excitation of pruriceptive neurons (Fig. 2). Thereby, pruritogens excite pruriceptive neurons through an indirect intracellular signalling coupling mechanism.

4.1 TRPV1 ${ }^{+}$pruriceptive neurons: Itch induced by histamine is mediated by the histamine receptor H1R, which is then coupled to TRPV1. How TRPV1 is opened by H1R-evoked signalling? H1R is a Gq coupled G-protein Coupled Receptor (GPCR). Activated Gq activates PLC $\beta$ and PLA2 resulting in increases in $\left[\mathrm{Ca}^{2+}\right]_{\mathrm{i}}$ and the liberation of arachidonic acid. Arachidonic acid is ultimately metabolized via lipooxygenase into various products, of which 12-hydroperoxyeicosatetraenoic acid (12-HPETE) was found to be critical for activating TRPV1 (Shim et al., 2007). Notably, PLC 33 is specifically required for H1Rmediated $\left[\mathrm{Ca}^{2+}\right]_{\mathrm{i}}$ increases in the DRG neurons and histamine elicited itching in mice, 
because both events were prevented by deleting PLC $\beta 3$ (Imamachi et al., 2009;Han et al., 2006).

Although histamine-elicited itch signalling mechanisms are well-defined, it is poorly understood regarding the itch signalling mechanisms evoked by serotonin and ET-1, both of which act also by activating the TRPV1 ${ }^{+}$pruriceptive neurons (Imamachi et al., 2009). This is probably due to unknown downstream ion channels activated by serotonin and ET-1. Nevertheless, PLC $\beta 3$ has been found to be essential for the itch signalling elicited by serotonin, but not by ET-1 (Imamachi et al., 2009). Imiquimod is another pruritogen that elicits itch by activating the TRPV $1^{+}$pruriceptive neurons (Kim et al., 2011). However, the signalling mechanisms underlying the actions of imiquimod are controversial. One group reported that the Toll-like receptor 7 (TLR7) is required for imiquimod to elicit intracellular signalling in DRG neurons (Liu et al., 2010a); another group found that imiquimod excites $\mathrm{TRPV}^{+}$neurons independently of TLR7, instead by inhibiting the background K(2P) channel and the voltage gated Kv1.1 and Kv1.2 channels (Kim et al., 2011;Lee et al., 2012). Altogether, TRPV1 ${ }^{+}$pruriceptive neurons seem to employ diverse intracellular signalling mechanisms to mediate the pruritogenic actions of histamine, serotonin, ET-1 and imiquimod.

4.2 TRPA1 ${ }^{+}$pruriceptive neurons: Several pruritogens, such as CQ, BAM8-22 and TSLP, activate intracellular signalling that couples to the TRPA1 ion channel, leading to the excitation of the TRPA $1^{+}$pruriceptive DRG neurons. BAM8-22 acts on MrgprC11, a Gq coupled GPCR, and TSLP binds to the TSLP receptor consisting of the IL7 receptor alpha (IL7R $\alpha$ ) chain and a TSLP-specific receptor chain (TSLPR). Although the two pruritogens act on different types of receptors, both appear to require Phospholipiase C (PLC) to excite TRPA1 (Wilson et al., 2011;Wilson et al., 2013b). By contrast, even though CQ and BAM822 bind to a similar type of Gq coupled GPCRs, CQ excites TRPA1 through released G $\beta \gamma$ without the involvement of PLC, while BAM8-22 activates TRPA1 via the PLC pathway without the need of G $\beta \gamma$ (Wilson et al., 2011). It remains uncertain how G $\beta \gamma$ activates TRPA1 and what are the detailed intracellular signalling mechanisms mobilized by PLC, leading to the excitation of TRPA1.

\section{Itch modulation}

TRPV1 and TRPA1 are the two main ion channels that mediate itching responses induced by a number of pruritogens. Agents or factors capable of enhancing activities of TRPV1 and TRPA1 should increase the intensity of the itch sensation (i.e. hyperkinesis) (Ikoma et al., 2006; Huang et al., 2006). For example, CQ not only directly excited TRPA1, but also potently enhanced TRPV1 responses through the PLC-PKC pathway (Than et al., 2013), suggesting that CQ contributes to itching not only by directly exciting TRPA1, but may also by indirectly facilitating TRPV1 mediated itching responses. Furthermore, the basal sensitivity of TRPV1 is enhanced in a subpopulation of TRPV $1^{+}$neurons co-expressing PKC $\beta$ II(Li et al., 2014). Enhanced functions of TRPV1 in the subpopulation of $\mathrm{TRPV}^{+} / \mathrm{PKC} \mathrm{II}^{+}$neurons could result in a higher sensitivity to either algogens or 
pruritogens or both, depending on whether this neuron population is pruriceptive or nociceptive, which remains to be elucidated.

\subsection{Modulation of itch by inflammatory mediators}

Pain sensitization caused by inflammation is often accompanied with increased sensation of itch. Inflammation is a typical feature of chronic itch such as atopic dermatitis.

The mechanisms underlying the sensitization of TRPV1 and TRPA1-mediated pain by various inflammatory mediators have been extensively studied in the past. These mechanisms may also apply to TRPV $1^{+}$and/or TRPA $1^{+}$pruriceptors -mediated itch. For example, the inflammatory mediator bradykinin enhances pain at least through potentiating TRPV1 and/or TRPA1 (Mizumura et al., 2009;Zhang et al., 2008). Interestingly, bradykinin also increased inflammation-evoked itch (hyperkinesis) and induced allokiness (touch-evoked itch) (Liang et al., 2012;Feng et al., 2014;Hosogi et al., 2006), suggesting that bradykinin sensitizes itch. However, it was not established whether bradykinin-elicited pruritus is mediated by TRPV1 or TRPA1. Another example is neurotrophic factors such as NGF and artemin, which are known to sensitize nociceptors and promote thermal and mechanical hyperalgesia (Pezet and McMahon, 2006; Malin et al., 2011;Malin et al., 2006;Zhang et al., 2005). NGF and artemin have also been recently shown to sensitize pruriceptors and thus enhance itching upon injected intradermally (Rukwied et al., 2013;Murota et al., 2012). Consistent with their role in regulating itch, the level of NGF and artemin was significantly elevated in the skin from patients with atopic dermatitis (Yamaguchi et al., 2009;Murota et al., 2012). Intriguingly, NGF sensitized only cowhage-induced itch, but hot histamine-induced itch(Rukwied et al., 2013), which is mainly mediated by TRPV1. It is therefore tempting to speculate that the NGF receptor TrkA is not expressed in the TRPV1 ${ }^{+}$pruriceptive neurons, but present in pruriceptive neurons that mediate the action of cowhage. It also suggests that cowhage and histamine elicit itch by activating distinct populations of pruriceptive neurons, consistent with previous reports (Davidson et al., 2007;Johanek et al., 2008). In addition to neurotrophic factors, several other inflammatory mediators including the PAR-2 agonist tryptase (Steinhoff et al., 2003;Akiyama et al., 2010), PGE2 (Belghiti et al., 2013) and 5-HT (Akiyama et al., 2010) were increased in chronic itch conditions. Scratching behaviour was attenuated by either blocking the action of these factors with antibodies or by blocking their acting receptors, showing that these inflammatory agents are involved in chronic itch. In a recent study of a mice model of cholestatic pruritus, there was a significant increase in the expression of the PAR-2 receptor and prostaglandin PGE2, leading to the sensitization of TRPV1 and consequently enhanced pain and itch (Belghiti et al., 2013), suggesting that tryptase and PGE2 enhance itching at least by targeting TRPV1.

\subsection{Modulation of itch by TRP ion channels}

TRPV1 and TRPA1 are directly involved in the itch transduction. This process can also be influenced by the actions of several other Thermo-TRP ion channels such as TRPV3 and TRPM8.

TRPV3: TRPV3 is a warm temperature-sensitive ion channel with an activation threshold of over $33^{\circ} \mathrm{C}$ (Peier et al., 2002;Moqrich et al., 2005;Xu et al., 2002;Smith et al., 2002). In 
contrast to TRPV1 and TRPA1, which are mainly expressed in peripheral sensory neurons and directly mediate pruritogens-induced excitation of neurons, TRPV3 is instead abundantly expressed in the epidermal keratinocytes in the skin with little expression in DRG (Peier et al., 2002; Xu et al., 2002). Consistent with its unique expression profile, TRPV3 was involved in skin barrier formation and hair morphogenesis (Cheng et al., 2010;Yamamoto-Kasai et al., 2012). Interestingly, activation of TRPV3 (e.g. by warm temperature) in keratinocytes led to the release of a diversity of factors including ATP (Mandadi et al., 2009), PGE2 (Huang et al., 2008), IL-1 $\alpha$ (Xu et al., 2006), nitric oxide (Miyamoto et al., 2011), TGF- $\alpha$ (Cheng et al., 2010) and NGF (Yoshioka et al., 2009). These factors aggravated inflammatory processes occurred in atopic dermatitis and altered skin structure (e.g. increased density of epidermal Cfibres) (Nilius and Biro, 2013;Yamamoto-Kasai et al., 2012). The released inflammatory factors may also sensitize pruriceptive fibres innervated in the skin, collectively resulting in an outcome of heightened itching responses. In further support of a critical role of TRPV3 in itch, overexpression of the highly active TRPV3 mutant G573S in mice caused even spontaneous dermatitis and scratching behaviour (Yoshioka et al., 2009). Increased scratching behaviour induced by AEW (acetone/ether mixture and water) in a dry skin mice model was absent in TRPV3 deficient mice (Yamamoto-Kasai et al., 2012). Furthermore, Both TRPV3 and TSLP expression were increased in skins from DS-Nh mice, an atopic dermatitis model (Yamamoto-Kasai et al., 2013). Interestingly, TSLP secretion was dependent on TRPV3 (Yamamoto-Kasai et al., 2013). Since it has recently been shown that $\mathrm{Ca}^{2+}$ is critical for TSLP secretion (Wilson et al., 2013b), it is very likely that TRPV3 promotes TSLP secretion by increasing $\mathrm{Ca}^{2+}$, and secreted TSLP, in turn, activates TRPA1 to elicit itching (Wilson et al., 2013b). Although it seems to be an appealing mechanism by which TRPV3 promotes itching, it remains to be validated in the future. Collectively, these findings implicate TRPV3 in the modulation of various types of itch. Furthermore, activation of TRPV3 by warm temperatures may provide a mechanistic explanation for the commonly known experience that warmth facilitates the itch sensation.

TRPV4: As with TRPV3, TRPV4 was also found to be expressed in keratinocytes and sensitive to warm temperatures $\left(>27^{\circ} \mathrm{C}\right.$ ) (Chung et al., 2003;Guler et al., 2002;Mihara et al., 2011; Chung et al., 2004). These features make TRPV4 another candidate that may play a role in itch associated with dermatitis. Indeed, the expression of TRPV4, together with TRPV3 and TRPA1, was increased in skin from patients with post-burn pruritus(Yang et al., 2014). However, the exact role of TRPV4 in dermatic pruritus needs more investigation.

TRPM8: TRPM8 is an ion channel that can be activated by cold $\left(<26^{\circ} \mathrm{C}\right)$ and cooling compounds such as menthol and icilin (McKemy et al., 2002;Chuang et al., 2004). It is mainly expressed in neurons from DRG and the trigeminal ganglia, consistent with its predominant role in the detection of cold in mice (Colburn et al., 2007;Dhaka et al., 2007;Bautista et al., 2007).

Cooling has a marked effect on the itch sensation. Researchers observed that cooling almost abolished itching in atopic dermatitis patients and histamine-induced itching in healthy 
subjects(Fruhstorfer et al., 1986). Skin cooling also diminished responses of spinal dorsal horn neurons elicited by intracutaneous microinjection of histamine (Carstens and Jinks, 1998). Furthermore, topical application of the TRPM8 agonist icilin alleviated pruritus (Han et al., 2012). However, whether the inhibitory effect of cooling or cooling compound on itching is mediated by TRPM8 has not been tested. TRPM8 knockout mice will help to resolve this question in the future. It is also unknown how activation of the cold thermoreceptors inhibits the itch sensation. It is likely to be mediated through a central mechanism, for example, by acting on the inhibitory mGluRII/III receptors in the dorsal horn, which also underlies the analgesic actions of icilin on neuropathic pain (Proudfoot et al., 2006).

\section{Concluding remarks:}

Peripheral sensory neurons contain multiple subpopulations of specialized pruriceptive neurons responsible for transducing various types of itch. TRPV $1^{+}$and TRPA $1^{+}$pruriceptive neurons represent two main distinct subpopulations of sensory neurons that respond to histamine and a diversity of other non-histaminergic pruritogens, respectively. These pruriceptive neurons employ diverse intracellular signalling mechanisms that couple the activation of pruritic receptors to the excitation of downstream ion channels (e.g. TRPV1, TRPA1 and other unknown TRP ion channels). Of note, different pruritogens activate different downstream ion channels even within the same type of pruriceptive neurons, highlighting the heterogeneity and diversity of pruriceptive neurons. Future efforts should be directed to identify other unknown downstream ion channels that are activated by various pruritogens. In addition to directly mediating the excitation of pruriceptive neurons (TRPV1, TRPA1), thermo-TRP ion channels (e.g. TRPV3 and TRPM8) are also involved in the modulation of itch through both peripheral and central mechanisms. A full understanding of the role of TRP ion channels in the itch transduction will be invaluable in developing effective anti-pruritic therapies by targeting these ion channels.

\section{References:}

Akiyama T, Carstens E (2013) Neural processing of itch. Neuroscience 250:697-714

Akiyama T, Carstens MI, Carstens E (2010) Enhanced scratching evoked by PAR-2 agonist and 5-HT but not histamine in a mouse model of chronic dry skin itch. Pain 151:378-383

Alemi F, Kwon E, Poole DP, Lieu T, Lyo V, Cattaruzza F, Cevikbas F, Steinhoff M, Nassini R, Materazzi S, Guerrero-Alba R, Valdez-Morales E, Cottrell GS, Schoonjans K, Geppetti P, Vanner SJ, Bunnett NW, Corvera CU (2013) The TGR5 receptor mediates bile acid-induced itch and analgesia. J Clin Invest 123:1513-1530

Amadesi S, Nie J, Vergnolle N, Cottrell GS, Grady EF, Trevisani M, Manni C, Geppetti P, McRoberts JA, Ennes H, Davis JB, Mayer EA, Bunnett NW (2004) Protease-activated receptor 2 sensitizes the capsaicin receptor transient receptor potential vanilloid receptor 1 to induce hyperalgesia. J Neurosci 24:4300-4312 
Bautista DM, Pellegrino M, Tsunozaki M (2013) TRPA1: A gatekeeper for inflammation. Annu Rev Physiol 75:181-200

Bautista DM, Siemens J, Glazer JM, Tsuruda PR, Basbaum AI, Stucky CL, Jordt SE, Julius D (2007) The menthol receptor TRPM8 is the principal detector of environmental cold.

Nature 448:204-208

Belghiti M, Estevez-Herrera J, Gimenez-Garzo C, Gonzalez-Usano A, Montoliu C, FerrerMontiel A, Felipo V, Planells-Cases R (2013) Potentiation of the transient receptor potential vanilloid 1 channel contributes to pruritogenesis in a rat model of liver disease. J Biol Chem 288:9675-9685

Bell JK, McQueen DS, Rees JL (2004) Involvement of histamine H4 and H1 receptors in scratching induced by histamine receptor agonists in Balb C mice. Br J Pharmacol 142:374380

Brederson JD, Kym PR, Szallasi A (2013) Targeting TRP channels for pain relief. Eur J Pharmacol 716:61-76

Carstens E, Jinks SL (1998) Skin cooling attenuates rat dorsal horn neuronal responses to intracutaneous histamine. Neuroreport 9:4145-4149

Cevikbas F, Wang X, Akiyama T, Kempkes C, Savinko T, Antal A, Kukova G, Buhl T, Ikoma A, Buddenkotte J, Soumelis V, Feld M, Alenius H, Dillon SR, Carstens E, Homey B, Basbaum A, Steinhoff M (2014) A sensory neuron-expressed IL-31 receptor mediates T helper cell-dependent itch: Involvement of TRPV1 and TRPA1. J Allergy Clin Immunol 133:448-460

Cheng X, Jin J, Hu L, Shen D, Dong XP, Samie MA, Knoff J, Eisinger B, Liu ML, Huang SM, Caterina MJ, Dempsey P, Michael LE, Dlugosz AA, Andrews NC, Clapham DE, Xu H (2010) TRP channel regulates EGFR signaling in hair morphogenesis and skin barrier formation. Cell 141:331-343

Chuang HH, Neuhausser WM, Julius D (2004) The super-cooling agent icilin reveals a mechanism of coincidence detection by a temperature-sensitive TRP channel. Neuron 43:859-869

Chung MK, Lee H, Caterina MJ (2003) Warm temperatures activate TRPV4 in mouse 308 keratinocytes. J Biol Chem 278:32037-32046

Chung MK, Lee H, Mizuno A, Suzuki M, Caterina MJ (2004) TRPV3 and TRPV4 mediate warmth-evoked currents in primary mouse keratinocytes. J Biol Chem 279:21569-21575

Colburn RW, Lubin ML, Stone DJ, Jr., Wang Y, Lawrence D, D'Andrea MR, Brandt MR, Liu Y, Flores CM, Qin N (2007) Attenuated cold sensitivity in TRPM8 null mice. Neuron 54:379-386

Dai Y, Moriyama T, Higashi T, Togashi K, Kobayashi K, Yamanaka H, Tominaga M, Noguchi K (2004) Proteinase-activated receptor 2-mediated potentiation of transient receptor potential vanilloid subfamily 1 activity reveals a mechanism for proteinase-induced inflammatory pain. J Neurosci 24:4293-4299 
Dai Y, Wang S, Tominaga M, Yamamoto S, Fukuoka T, Higashi T, Kobayashi K, Obata K, Yamanaka H, Noguchi K (2007) Sensitization of TRPA1 by PAR2 contributes to the sensation of inflammatory pain. J Clin Invest 117:1979-1987

Davidson S, Zhang X, Khasabov SG, Moser HR, Honda CN, Simone DA, Giesler GJ, Jr. (2012) Pruriceptive spinothalamic tract neurons: physiological properties and projection targets in the primate. J Neurophysiol 108:1711-1723

Davidson S, Zhang X, Yoon CH, Khasabov SG, Simone DA, Giesler GJ, Jr. (2007) The itchproducing agents histamine and cowhage activate separate populations of primate spinothalamic tract neurons. J Neurosci 27:10007-10014

Dhaka A, Murray AN, Mathur J, Earley TJ, Petrus MJ, Patapoutian A (2007) TRPM8 is required for cold sensation in mice. Neuron 54:371-378

Feng J, Chen Y, Xiong J, Chen X, Liang J, Ji W (2014) The kinin B1 receptor mediates alloknesis in a murine model of inflammation. Neurosci Lett 560:31-35

Fernandes ES, Vong CT, Quek S, Cheong J, Awal S, Gentry C, Aubdool AA, Liang L, Bodkin JV, Bevan S, Heads R, Brain SD (2013) Superoxide generation and leukocyte accumulation: key elements in the mediation of leukotriene B(4)-induced itch by transient receptor potential ankyrin 1 and transient receptor potential vanilloid 1. FASEB J 27:16641673

Fruhstorfer H, Hermanns M, Latzke L (1986) The effects of thermal stimulation on clinical and experimental itch. Pain 24:259-269

Gomes LO, Hara DB, Rae GA (2012) Endothelin-1 induces itch and pain in the mouse cheek model. Life Sci 91:628-633

Grant AD, Cottrell GS, Amadesi S, Trevisani M, Nicoletti P, Materazzi S, Altier C, Cenac N, Zamponi GW, Bautista-Cruz F, Lopez CB, Joseph EK, Levine JD, Liedtke W, Vanner S, Vergnolle N, Geppetti P, Bunnett NW (2007) Protease-activated receptor 2 sensitizes the transient receptor potential vanilloid 4 ion channel to cause mechanical hyperalgesia in mice 2. J Physiol 578:715-733

Greaves MW (2007) Recent advances in pathophysiology and current management of itch. Ann Acad Med Singapore 36:788-792

Greaves MW, Davies MG (1982) Histamine receptors in human skin: indirect evidence. Br J Dermatol 107 Suppl 23:101-105

Guler AD, Lee H, Iida T, Shimizu I, Tominaga M, Caterina M (2002) Heat-evoked activation of the ion channel, TRPV4. J Neurosci 22:6408-6414

Han JH, Choi HK, Kim SJ (2012) Topical TRPM8 agonist (icilin) relieved vulva pruritus originating from lichen sclerosus et atrophicus. Acta Derm Venereol 92:561-562

Han L, Ma C, Liu Q, Weng HJ, Cui Y, Tang Z, Kim Y, Nie H, Qu L, Patel KN, Li Z, McNeil B, He S, Guan Y, Xiao B, Lamotte RH, Dong X (2013) A subpopulation of nociceptors specifically linked to itch. Nat Neurosci 16:174-182 
Han SK, Mancino V, Simon MI (2006) Phospholipase Cbeta 3 mediates the scratching response activated by the histamine $\mathrm{H} 1$ receptor on $\mathrm{C}$-fiber nociceptive neurons. Neuron 52:691-703

Hosogi M, Schmelz M, Miyachi Y, Ikoma A (2006) Bradykinin is a potent pruritogen in atopic dermatitis: a switch from pain to itch. Pain 126:16-23

Huang J, Zhang X, McNaughton PA (2006) Modulation of temperature-sensitive TRP channels. Semin Cell Dev Biol 17:638-645

Huang SM, Lee H, Chung MK, Park U, Yu YY, Bradshaw HB, Coulombe PA, Walker JM, Caterina MJ (2008) Overexpressed transient receptor potential vanilloid 3 ion channels in skin keratinocytes modulate pain sensitivity via prostaglandin E2. J Neurosci 28:1372713737

Ikoma A, Steinhoff M, Stander S, Yosipovitch G, Schmelz M (2006) The neurobiology of itch. Nat Rev Neurosci 7:535-547

Imamachi N, Park GH, Lee H, Anderson DJ, Simon MI, Basbaum AI, Han SK (2009) TRPV1-expressing primary afferents generate behavioral responses to pruritogens via multiple mechanisms. Proc Natl Acad Sci U S A 106:11330-11335

Jariwala SP, Abrams E, Benson A, Fodeman J, Zheng T (2011) The role of thymic stromal lymphopoietin in the immunopathogenesis of atopic dermatitis. Clin Exp Allergy 41:15151520

Johanek LM, Meyer RA, Friedman RM, Greenquist KW, Shim B, Borzan J, Hartke T, Lamotte RH, Ringkamp M (2008) A role for polymodal C-fiber afferents in nonhistaminergic itch. J Neurosci 28:7659-7669

Johanek LM, Meyer RA, Hartke T, Hobelmann JG, Maine DN, Lamotte RH, Ringkamp M (2007) Psychophysical and physiological evidence for parallel afferent pathways mediating the sensation of itch. J Neurosci 27:7490-7497

Julius D (2013) TRP channels and pain. Annu Rev Cell Dev Biol 29:355-384

Kardon AP, Polgar E, Hachisuka J, Snyder LM, Cameron D, Savage S, Cai X, Karnup S, Fan CR, Hemenway GM, Bernard CS, Schwartz ES, Nagase H, Schwarzer C, Watanabe M, Furuta T, Kaneko T, Koerber HR, Todd AJ, Ross SE (2014) Dynorphin acts as a neuromodulator to inhibit itch in the dorsal horn of the spinal cord. Neuron 82:573-586

Kido-Nakahara M, Buddenkotte J, Kempkes C, Ikoma A, Cevikbas F, Akiyama T, Nunes F, Seeliger S, Hasdemir B, Mess C, Buhl T, Sulk M, Muller FU, Metze D, Bunnett NW, Bhargava A, Carstens E, Furue M, Steinhoff M (2014) Neural peptidase endothelinconverting enzyme 1 regulates endothelin 1-induced pruritus. J Clin Invest 124:2683-2695

Kim SJ, Park GH, Kim D, Lee J, Min H, Wall E, Lee CJ, Simon MI, Lee SJ, Han SK (2011) Analysis of cellular and behavioral responses to imiquimod reveals a unique itch pathway in transient receptor potential vanilloid 1 (TRPV1)-expressing neurons

3. Proc Natl Acad Sci U S A 108:3371-3376 
Kremer AE, Martens JJ, Kulik W, Rueff F, Kuiper EM, van Buuren HR, van Erpecum KJ, Kondrackiene J, Prieto J, Rust C, Geenes VL, Williamson C, Moolenaar WH, Beuers U, Oude Elferink RP (2010) Lysophosphatidic acid is a potential mediator of cholestatic pruritus. Gastroenterology 139:1008-18, 1018

Lagerstrom MC, Rogoz K, Abrahamsen B, Persson E, Reinius B, Nordenankar K, Olund C, Smith C, Mendez JA, Chen ZF, Wood JN, Wallen-Mackenzie A, Kullander K (2010) VGLUT2-dependent sensory neurons in the TRPV1 population regulate pain and itch. Neuron 68:529-542

Lamotte RH, Dong X, Ringkamp M (2014) Sensory neurons and circuits mediating itch. Nat Rev Neurosci 15:19-31

Lee J, Kim T, Hong J, Woo J, Min H, Hwang E, Lee SJ, Lee CJ (2012) Imiquimod enhances excitability of dorsal root ganglion neurons by inhibiting background (K(2P)) and voltagegated $(\mathrm{K}(\mathrm{v}) 1.1$ and $\mathrm{K}(\mathrm{v}) 1.2)$ potassium channels. Mol Pain 8:2

Li L, Hasan R, Zhang X (2014) The Basal Thermal Sensitivity of the TRPV1 Ion Channel Is Determined by PKCbetaII. J Neurosci 34:8246-8258

Liang J, He Y, Ji W (2012) Bradykinin-evoked scratching responses in complete Freund's adjuvant-inflamed skin through activation of B1 receptor. Exp Biol Med (Maywood) 237:318-326

Liang J, Kawamata T, Ji W (2010) Molecular signaling of pruritus induced by endothelin-1 in mice. Exp Biol Med (Maywood ) 235:1300-1305

Lieu T, Jayaweera G, Zhao P, Poole DP, Jensen D, Grace M, McIntyre P, Bron R, Wilson YM, Krappitz M, Haerteis S, Korbmacher C, Steinhoff MS, Nassini R, Materazzi S, Geppetti P, Corvera CU, Bunnett NW (2014) The Bile Acid Receptor TGR5 Activates the TRPA1 Channel to Induce Itch in Mice. Gastroenterology

Liu B, Escalera J, Balakrishna S, Fan L, Caceres AI, Robinson E, Sui A, McKay MC, McAlexander MA, Herrick CA, Jordt SE (2013) TRPA1 controls inflammation and pruritogen responses in allergic contact dermatitis. FASEB J 27:3549-3563

Liu Q, Sikand P, Ma C, Tang Z, Han L, Li Z, Sun S, Lamotte RH, Dong X (2012) Mechanisms of itch evoked by beta-alanine. J Neurosci 32:14532-14537

Liu Q, Tang Z, Surdenikova L, Kim S, Patel KN, Kim A, Ru F, Guan Y, Weng HJ, Geng Y, Undem BJ, Kollarik M, Chen ZF, Anderson DJ, Dong X (2009) Sensory neuron-specific GPCR Mrgprs are itch receptors mediating chloroquine-induced pruritus. Cell 139:1353-1365

Liu Q, Weng HJ, Patel KN, Tang Z, Bai H, Steinhoff M, Dong X (2011) The distinct roles of two GPCRs, MrgprC11 and PAR2, in itch and hyperalgesia. Sci Signal 4:ra45

Liu T, Ji RR (2012) Oxidative stress induces itch via activation of transient receptor potential subtype ankyrin 1 in mice. Neurosci Bull 28:145-154

Liu T, Xu ZZ, Park CK, Berta T, Ji RR (2010a) Toll-like receptor 7 mediates pruritus. Nat Neurosci 13:1460-1462 
Liu Y, Abdel SO, Zhang L, Duan B, Tong Q, Lopes C, Ji RR, Lowell BB, Ma Q (2010b) VGLUT2-dependent glutamate release from nociceptors is required to sense pain and suppress itch. Neuron 68:543-556

Malin S, Molliver D, Christianson JA, Schwartz ES, Cornuet P, Albers KM, Davis BM (2011) TRPV1 and TRPA1 function and modulation are target tissue dependent. J Neurosci 31:10516-10528

Malin SA, Molliver DC, Koerber HR, Cornuet P, Frye R, Albers KM, Davis BM (2006) Glial cell line-derived neurotrophic factor family members sensitize nociceptors in vitro and produce thermal hyperalgesia in vivo. J Neurosci 26:8588-8599

Mandadi S, Sokabe T, Shibasaki K, Katanosaka K, Mizuno A, Moqrich A, Patapoutian A, Fukumi-Tominaga T, Mizumura K, Tominaga M (2009) TRPV3 in keratinocytes transmits temperature information to sensory neurons via ATP. Pflugers Arch

McKemy DD, Neuhausser WM, Julius D (2002) Identification of a cold receptor reveals a general role for TRP channels in thermosensation. Nature 416:52-58

McMahon SB, Koltzenburg M (1992) Itching for an explanation. Trends Neurosci 15:497501

Mihara H, Boudaka A, Sugiyama T, Moriyama Y, Tominaga M (2011) Transient receptor potential vanilloid 4 (TRPV4)-dependent calcium influx and ATP release in mouse oesophageal keratinocytes. J Physiol 589:3471-3482

Miyamoto T, Petrus MJ, Dubin AE, Patapoutian A (2011) TRPV3 regulates nitric oxide synthase-independent nitric oxide synthesis in the skin. Nat Commun 2:369

Mizumura K, Sugiura T, Katanosaka K, Banik RK, Kozaki Y (2009) Excitation and sensitization of nociceptors by bradykinin: what do we know? Exp Brain Res 196:53-65

Moqrich A, Hwang SW, Earley TJ, Petrus MJ, Murray AN, Spencer KS, Andahazy M, Story GM, Patapoutian A (2005) Impaired thermosensation in mice lacking TRPV3, a heat and camphor sensor in the skin. Science 307:1468-1472

Murota H, Izumi M, Abd El-Latif MI, Nishioka M, Terao M, Tani M, Matsui S, Sano S, Katayama I (2012) Artemin causes hypersensitivity to warm sensation, mimicking warmthprovoked pruritus in atopic dermatitis. J Allergy Clin Immunol 130:671-682

Nakagawa H, Hiura A (2013) Four Possible Itching Pathways Related to the TRPV1 Channel, Histamine, PAR-2 and Serotonin. Malays J Med Sci 20:5-12

Nilius B, Biro T (2013) TRPV3: a 'more than skinny' channel. Exp Dermatol 22:447-452

Nilius B, Owsianik G (2011) The transient receptor potential family of ion channels. Genome Biol 12:218

Nilius B, Owsianik G, Voets T, Peters JA (2007) Transient receptor potential cation channels in disease. Physiol Rev 87:165-217 
Oh MH, Oh SY, Lu J, Lou H, Myers AC, Zhu Z, Zheng T (2013) TRPA1-dependent pruritus in IL-13-induced chronic atopic dermatitis. J Immunol 191:5371-5382

Papoiu AD, Tey HL, Coghill RC, Wang H, Yosipovitch G (2011) Cowhage-induced itch as an experimental model for pruritus. A comparative study with histamine-induced itch. PLoS One 6:e17786

Patel KN, Dong X (2010) An itch to be scratched. Neuron 68:334-339

Peier AM, Reeve AJ, Andersson DA, Moqrich A, Earley TJ, Hergarden AC, Story GM, Colley S, Hogenesch JB, McIntyre P, Bevan S, Patapoutian A (2002) A heat-sensitive TRP channel expressed in keratinocytes. Science 296:2046-2049

Pezet S, McMahon SB (2006) Neurotrophins: mediators and modulators of pain. Annu Rev Neurosci 29:507-538

Proudfoot CJ, Garry EM, Cottrell DF, Rosie R, Anderson H, Robertson DC, FleetwoodWalker SM, Mitchell R (2006) Analgesia mediated by the TRPM8 cold receptor in chronic neuropathic pain. Curr Biol 16:1591-1605

Rabenhorst A, Hartmann K (2014) Interleukin-31: a novel diagnostic marker of allergic diseases. Curr Allergy Asthma Rep 14:423

Reddy VB, Iuga AO, Shimada SG, Lamotte RH, Lerner EA (2008) Cowhage-evoked itch is mediated by a novel cysteine protease: a ligand of protease-activated receptors. J Neurosci 28:4331-4335

Ringkamp M, Schepers RJ, Shimada SG, Johanek LM, Hartke TV, Borzan J, Shim B, Lamotte RH, Meyer RA (2011) A role for nociceptive, myelinated nerve fibers in itch sensation. J Neurosci 31:14841-14849

Roberson DP, Gudes S, Sprague JM, Patoski HA, Robson VK, Blasl F, Duan B, Oh SB, Bean BP, Ma Q, Binshtok AM, Woolf CJ (2013) Activity-dependent silencing reveals functionally distinct itch-generating sensory neurons. Nat Neurosci 16:910-918

Ross SE, Mardinly AR, McCord AE, Zurawski J, Cohen S, Jung C, Hu L, Mok SI, Shah A, Savner EM, Tolias C, Corfas R, Chen S, Inquimbert P, Xu Y, McInnes RR, Rice FL, Corfas G, Ma Q, Woolf CJ, Greenberg ME (2010) Loss of inhibitory interneurons in the dorsal spinal cord and elevated itch in Bhlhb5 mutant mice. Neuron 65:886-898

Rossbach K, Nassenstein C, Gschwandtner M, Schnell D, Sander K, Seifert R, Stark H, Kietzmann M, Baumer W (2011) Histamine H1, H3 and H4 receptors are involved in pruritus. Neuroscience 190:89-102

Rukwied RR, Main M, Weinkauf B, Schmelz M (2013) NGF sensitizes nociceptors for cowhage- but not histamine-induced itch in human skin. J Invest Dermatol 133:268-270

SHELLEY WB, ARTHUR RP (1955) Mucunain, the active pruritogenic proteinase of cowhage. Science 122:469-470 
Shim WS, Tak MH, Lee MH, Kim M, Kim M, Koo JY, Lee CH, Kim M, Oh U (2007) TRPV1 mediates histamine-induced itching via the activation of phospholipase A2 and 12lipoxygenase. J Neurosci 27:2331-2337

Smith GD, Gunthorpe MJ, Kelsell RE, Hayes PD, Reilly P, Facer P, Wright JE, Jerman JC, Walhin JP, Ooi L, Egerton J, Charles KJ, Smart D, Randall AD, Anand P, Davis JB (2002) TRPV3 is a temperature-sensitive vanilloid receptor-like protein. Nature 418:186-190

Steinhoff M, Neisius U, Ikoma A, Fartasch M, Heyer G, Skov PS, Luger TA, Schmelz M (2003) Proteinase-activated receptor-2 mediates itch: a novel pathway for pruritus in human skin. J Neurosci 23:6176-6180

Story GM, Peier AM, Reeve AJ, Eid SR, Mosbacher J, Hricik TR, Earley TJ, Hergarden AC, Andersson DA, Hwang SW, McIntyre P, Jegla T, Bevan S, Patapoutian A (2003) ANKTM1, a TRP-like channel expressed in nociceptive neurons, is activated by cold temperatures. Cell 112:819-829

Than JY, Li L, Hasan R, Zhang X (2013) Excitation and modulation of TRPA1, TRPV1, and TRPM8 channel-expressing sensory neurons by the pruritogen chloroquine. J Biol Chem 288:12818-12827

Trentin PG, Fernandes MB, D'Orleans-Juste P, Rae GA (2006) Endothelin-1 causes pruritus in mice. Exp Biol Med (Maywood ) 231:1146-1151

Venkatachalam K, Montell C (2007) TRP channels. Annu Rev Biochem 76:387-417

Wilson SR, Gerhold KA, Bifolck-Fisher A, Liu Q, Patel KN, Dong X, Bautista DM (2011) TRPA1 is required for histamine-independent, Mas-related G protein-coupled receptormediated itch. Nat Neurosci 14:595-602

Wilson SR, Nelson AM, Batia L, Morita T, Estandian D, Owens DM, Lumpkin EA, Bautista DM (2013a) The ion channel TRPA1 is required for chronic itch. J Neurosci 33:9283-9294

Wilson SR, The L, Batia LM, Beattie K, Katibah GE, McClain SP, Pellegrino M, Estandian DM, Bautista DM (2013b) The Epithelial Cell-Derived Atopic Dermatitis Cytokine TSLP Activates Neurons to Induce Itch. Cell 155:285-295

Xu H, Delling M, Jun JC, Clapham DE (2006) Oregano, thyme and clove-derived flavors and skin sensitizers activate specific TRP channels. Nat Neurosci 9:628-635

Xu H, Ramsey IS, Kotecha SA, Moran MM, Chong JA, Lawson D, Ge P, Lilly J, SilosSantiago I, Xie Y, DiStefano PS, Curtis R, Clapham DE (2002) TRPV3 is a calciumpermeable temperature-sensitive cation channel. Nature 418:181-186

Yamaguchi J, Aihara M, Kobayashi Y, Kambara T, Ikezawa Z (2009) Quantitative analysis of nerve growth factor (NGF) in the atopic dermatitis and psoriasis horny layer and effect of treatment on NGF in atopic dermatitis. J Dermatol Sci 53:48-54

Yamamoto-Kasai E, Imura K, Yasui K, Shichijou M, Oshima I, Hirasawa T, Sakata T, Yoshioka T (2012) TRPV3 as a therapeutic target for itch. J Invest Dermatol 132:2109-2112 
Yamamoto-Kasai E, Yasui K, Shichijo M, Sakata T, Yoshioka T (2013) Impact of TRPV3 on the development of allergic dermatitis as a dendritic cell modulator. Exp Dermatol 22:820824

Yang YS, Cho SI, Choi MG, Choi YH, Kwak IS, Park CW, Kim HO (2014) Increased Expression of Three Types of Transient Receptor Potential Channels (TRPA1, TRPV4 and TRPV3) in Burn Scars with Post-burn Pruritus. Acta Derm Venereol

Yoshioka T, Imura K, Asakawa M, Suzuki M, Oshima I, Hirasawa T, Sakata T, Horikawa T, Arimura A (2009) Impact of the Gly573Ser substitution in TRPV3 on the development of allergic and pruritic dermatitis in mice. J Invest Dermatol 129:714-722

Yosipovitch G, Greaves MW, Schmelz M (2003) Itch. Lancet 361:690-694

Zhang X, Huang J, McNaughton PA (2005) NGF rapidly increases membrane expression of TRPV1 heat-gated ion channels. EMBO J 24:4211-4223

Zhang X, Li L, McNaughton PA (2008) Proinflammatory mediators modulate the heatactivated ion channel TRPV1 via the scaffolding protein AKAP79/150. Neuron 59:450-461 
Table 1: Pruritogens, pruritic receptors and their acting downstream TRP ion channels

\begin{tabular}{|c|c|c|c|c|}
\hline \multicolumn{2}{|c|}{ Pruritogens } & \multirow{2}{*}{$\begin{array}{c}\text { Pruritic receptors } \\
\text { H1R, H3R and } \\
\text { H4R }\end{array}$} & \multirow{2}{*}{$\begin{array}{c}\begin{array}{c}\text { Excited ion } \\
\text { channels }\end{array} \\
\\
\text { TRPV1, } \\
\text { others? }\end{array}$} & \multirow{2}{*}{$\begin{array}{c}\text { References } \\
\text { (Shim et al., } \\
\text { 2007; Roberson et al., } \\
\text { 2013;Bell et al., } \\
\text { 2004; Rossbach et al., } \\
\text { 2011; Imamachi et al., } \\
\text { 2009) }\end{array}$} \\
\hline Histaminergic & Histamine & & & \\
\hline \multirow{11}{*}{$\begin{array}{c}\text { Non- } \\
\text { histaminergic }\end{array}$} & Chloroquine & MrgprA3 & $\begin{array}{l}\text { TRPA1, } \\
\text { TRPC3 }\end{array}$ & $\begin{array}{l}\text { (Wilson et al., 2011;Liu } \\
\text { et al., 2009; Than et al., } \\
\text { 2013) }\end{array}$ \\
\hline & $\begin{array}{l}\text { SLIGRL, } \\
\text { BAM8-22 }\end{array}$ & MrgprC11 & TRPA1 & $\begin{array}{l}\text { (Wilson et al., 2011;Liu } \\
\text { et al., 2011;Roberson et } \\
\text { al., 2013;Liu et al., } \\
\text { 2009) }\end{array}$ \\
\hline & 5-HT & 5-HT2A & ? & $\begin{array}{l}\text { (Imamachi et al., } \\
\text { 2009;Akiyama et al., } \\
\text { 2010) }\end{array}$ \\
\hline & ET-1 & ETAR & $?$ & $\begin{array}{l}\text { (Liang et al., } \\
\text { 2010;Kido-Nakahara et } \\
\text { al., 2014;Trentin et al., } \\
\text { 2006;Gomes et al., } \\
\text { 2012) }\end{array}$ \\
\hline & Cowhage & PAR2 and PAR4 & TRPA1? & (Reddy et al., 2008) \\
\hline & IL-31 & IL-31RA & $\begin{array}{l}\text { TRPV1, } \\
\text { TRPA1 }\end{array}$ & (Cevikbas et al., 2014) \\
\hline & TSLP & TSLPR & TRPA1 & (Wilson et al., 2013b) \\
\hline & LTB4 & BLT1 & $\begin{array}{l}\text { TRPV1, } \\
\text { TRPA1 }\end{array}$ & (Fernandes et al., 2013) \\
\hline & $\beta$-alanine & MrgprD & $?$ & (Liu et al., 2012) \\
\hline & Bile acids & TGR5 & $?$ & (Alemi et al., 2013) \\
\hline & LPA & LPA4? & $?$ & (Kremer et al., 2010) \\
\hline
\end{tabular}


A

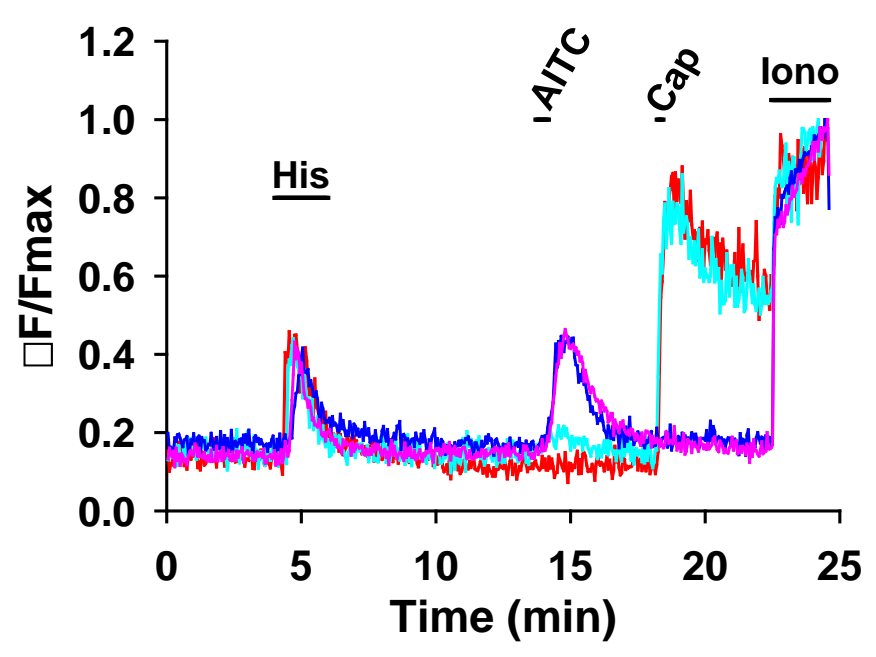

B

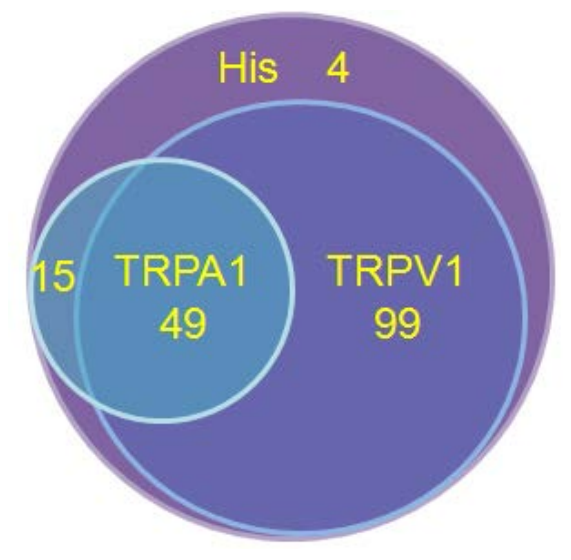

Figure 1. Responses of DRG neurons elicited by histamine. (A) Examples of responses of $\left[\mathrm{Ca}^{2+}\right]_{\mathrm{i}}$ from 4 DRG neurons stimulated with histamine (His, $\left.100 \mu \mathrm{M}\right)$, AITC $(100 \mu \mathrm{M})$, an agonist to TRPA1, and capsaicin (Cap, $0.5 \mu \mathrm{M}$ ), an agonist to TRPV1. Ionomycin (Iono, $10 \mu \mathrm{M}$ ) was added at the end of the experiments. (B) The Venn diagram summary of different neuron populations co-expressing TRPV1 and/or TRPA1 within histamine excited neurons from experiments similar to those in A. The number of neurons is shown for each population and was obtained from a total of 2693 neonatal DRG neurons, as before (Than et al., 2013)

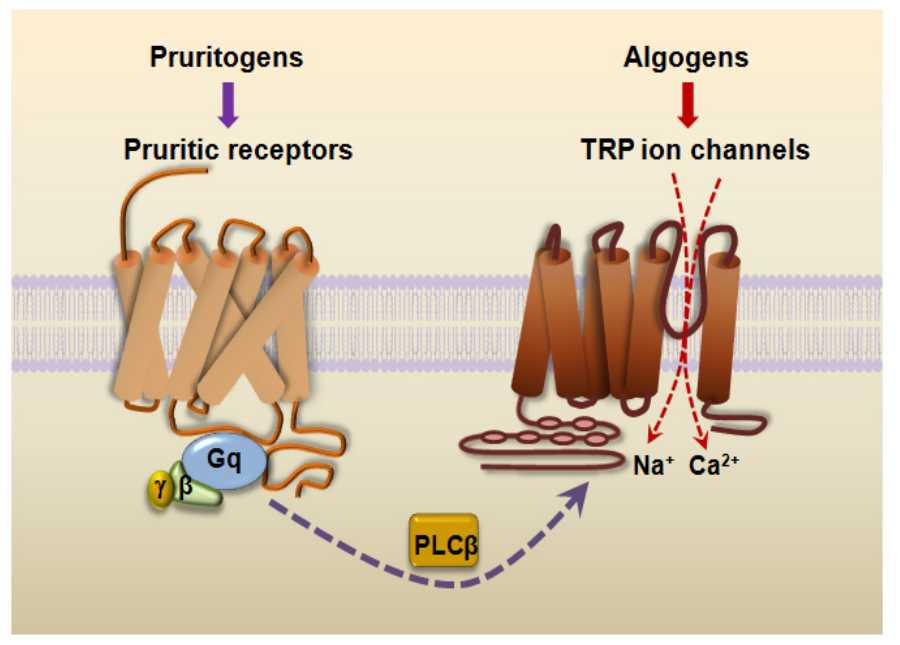

Figure 2. A schematic diagram depicting the excitation of sensory neurons elicited by pruritogens through intracellular signalling coupling mechanisms. Following binding to corresponding pruritic receptors (mostly G protein coupled receptors), pruritogens excites pruriceptive neurons by activating intracellular signalling messengers (e.g. PLC $\beta$ ), which are then coupled to a downstream ion channel (e.g. TRP ion channels), leading to the influx of cation ions and subsequent neuron excitation. Noxious stimuli (algogens), however, directly open TRP ion channels resulting in neuron excitation. 